\title{
Scaffolding: Meaningful Sequences during the Training Phase of a Learning Potential Test?
}

\author{
Geerdina M. van der Aalsvoort, ${ }^{1}$ Floor van Loo, ${ }^{2}$ and Paul van Geert ${ }^{3}$ \\ ${ }^{1}$ School of Education, Saxion University of Applied Sciences, Handelskade 75, 7417 DH Deventer, The Netherlands \\ ${ }^{2}$ Research Centre of Education, Faculty of Education, Utrecht University of Applied Sciences, P.O. Box 14007, \\ $3584 \mathrm{CH}$ Utrecht, The Netherlands \\ ${ }^{3}$ Department of Developmental Psychology, University of Groningen, Grote Kruisstraat 2, 9712 TC Groningen, The Netherlands
}

Correspondence should be addressed to Geerdina M. van der Aalsvoort, g.m.vanderaalsvoort@saxion.nl

Received 21 December 2011; Accepted 19 February 2012

Academic Editor: Y. Xie

Copyright (๑) 2012 Geerdina M. van der Aalsvoort et al. This is an open access article distributed under the Creative Commons Attribution License, which permits unrestricted use, distribution, and reproduction in any medium, provided the original work is properly cited.

\begin{abstract}
This study aimed at revealing scaffolding sequences of behavior during the training phase of a learning potential test. Involved were two conditions of four children with learning gains and four children without learning gains after the training phase of the subtest Classification of the Application of Cognitive Functions Scales. This subtest included three tasks: classification of color, form, and size. A dynamic system approach was used to describe the existence of four types of scaffolding that supposedly underlie the training phase. A microgenetic data analysis of the videotapes allowed coding of the behaviors of the training phase from the children and the diagnostician. Four sequences of scaffolding were defined, asking for attention of the child and giving attention as a child, asking for understanding of the child and responding to the diagnostician as a child; giving feedback to the child and responding to the feedback of the child, and offering strategies to the child and using strategies as a child. The results revealed no significant differences in the number of sequences between the conditions. Changes, however, were exposed in the relative frequency of each type of scaffolding from subtask 1 to 3. Moreover, the hierarchy of frequency of sequences differed between the conditions. The description of the findings of a boy from each condition in frequency per sequence, rainbow plot, and representative transcript revealed emergence of sequences over time. The findings are discussed with regard to theoretical reflections and methodological issues.
\end{abstract}

\section{Introduction}

1.1. Measuring Intelligence. Learning potential tests have been developed for the purpose of detecting the required instruction to elicit underlying thinking processes. These tests have been available as diagnostic measures for well over 50 years. They allow a better understanding of learning processes as they take into account influences of social environment during the testing procedure [1]. Tests like these also elicit progress in learning during the training phase when the diagnostician assists the child by offering help that appeals to the child's zone of proximal development. This zone is described by Vygotsky [2] when he explained that cognitive functioning occurs in the zones of actual and proximal development. Information about both zones is required to understand children's cognitive functioning. Learning potential tests embed intervention within the assessment, usually by offering a pretest followed by training or intervention and a posttest. Research findings from Day et al. [3], Lidz and Van der Aalsvoort [4], Resing [5], and Van der Aalsvoort and Lidz [6] show that static testing procedures, combined with learning potential tests, are better predictors of the abilities of individual children than each of these measures alone. Particularly with regard to understanding the instructional needs of a child with learning difficulties, information about the child's learning potential is essential.

1.2. The Training Phase of a Learning Potential Test. The training phase is a typical part of a learning potential test. During the child's participation in the training phase, the diagnostician can observe the child's behavior to notice how he complies to different kinds of support. The diagnostician can also observe the child's strengths and weaknesses while 


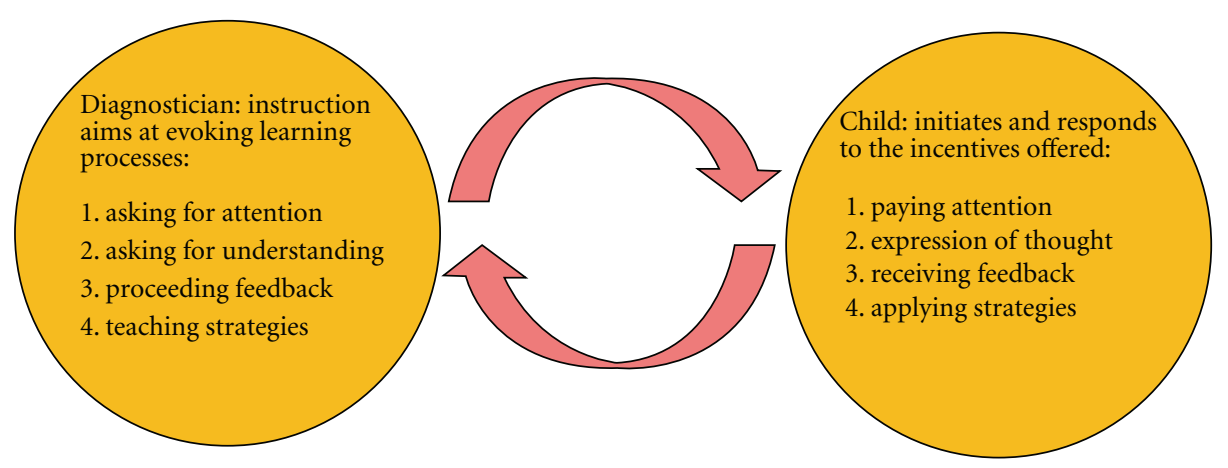

FIGURE 1: A dynamic model of the sequences between diagnostician and child during the training phase.

performing. Thus, both the child's current levels of functioning as well as his responses to intervention are tapped [7]. The assessment requires an experienced diagnostician who is aware of his role in the interaction process. It is during the interaction process that learning processes are elicited from the child. Supposedly, the diagnostician strives for effective interaction with the child to allow optimal opportunity to achieve learning gains. Therefore, the quality of the diagnostician's behavior requires several criteria that must be met. These criteria are based on the theory of mediated learning experiences of Feuerstein [8] and combined, adapted, and supplemented by others [9-12]. The criteria take into consideration that the training phase includes interactions between child and diagnostician: they share the experience and influence each other continuously; reciprocal processes emerge as mutually formed unique interaction sequences between diagnostician and child during the training phase. Although learning potential tests aim at revealing learning processes and emphasize the importance of the interaction between diagnostician and child, the result of the posttest is expressed as an outcome, namely, learning gains. The outcome does not reveal how mutual formed interaction processes are related to the learning processes that are considered to lie beneath the learning gains. We know little about the way mutual interactions become effective and how they develop into learning gains. The investigation presented below addresses the concerns by analyzing the interaction processes that occur during the training phase of a learning potential test. To our knowledge this type of study has not been carried out before.

Aiming at showing how interaction processes during learning potential tests underlie learning gains a dynamic systems approach was chosen $[13,14]$. This approach supports a deeper understanding of interaction sequences as it considers processes of change and development as complex dynamic systems [15-18]. A dynamic system is based on self-organization of interdependent variables. Interaction between the interdependent variables tends to move into a preferred state over time. "State" refers to the interacting variables that are measured. Our study considers interactions between child and diagnostician during the training phase as a dynamic system. An emergence of interactions is started by the diagnostician to elicit learning processes from the child; the child responds to the diagnostician's intentions and elicits responding behavior of the diagnostician et cetera; a stream of interactions takes place that moves into stable patterns. Thus, the training phase is seen as a dynamic system that seeks stability within the teaching-learning event, and this supposedly leads to learning gains with the child.

\subsection{Scaffolding as the Main Process to Describe the Training} Phase from a Dynamic Systems Approach. In social-cognitive theory, a child's learning process is regarded as something that comes from self-regulatory processes of a child when he is offered a task [19]. This perspective stresses how students select and choose appropriate actions and how environmental influences can assist in developing these skills. The influence from the environment can be defined as "scaffolding" or providing assistance to a student on asneeded based and fading the assistance as the competence of the student increases [20]. Scaffolding is supposedly an inherently social process that is shared between teacher and student [19] and its purpose is to support learners as well as develop their knowledge and skills needed to perform future tasks [21]. Scaffolding includes structuring or setting out the task in a comprehendible way as well as problematizing, such as posing questions that elicit metacognitive activities from the child. Scaffolding is temporarily contingent: the teacher is responsive to the current level of the student which the student, otherwise, might, otherwise, not be able to complete [22]. Scaffolding from a dynamic systems perspective $[13,14]$, however, suggests a further step in this process. Responsiveness from the teacher coincides with responsiveness from the student. Scaffolding unfolds as a dynamic process that is influenced by both partners in the task. Only by observing the teacher and the child in the task in time, it can be revealed whether scaffolding indeed unfolds. A microgenetic approach, therefore, seems the best way to observe the scaffolding process $[23,24]$.

1.4. A Dynamic Model of Sequences in the Training Phase. The dynamic model that is presented in Figure 1 shows the behaviors that supposedly emerge during the training phase as contributors to learning gains through interaction patterns, or sequences. The arrows between diagnostician 
and child refer to the dynamic process of continuous and mutual influence of behaviors during the training phase.

The following four sequences are to be expected based upon the model in Figure 1. They were tested in the study. The operationalizations of the sequences of scaffolding are derived from Lidz [25] with regard to diagnostician behavior and from Lidz [10] with regard to child behavior.

(1) When the Diagnostician Asks for Attention the Child Shows Task-Oriented Behavior. The diagnostician actively attempts to (re)focus the child's attention and to maintain the child's involvement. He supports the child to orient, both nonverbal and verbal towards the task. Examples of behavior of the diagnostician: "Look at this," "I want you to...," "Watch!," "Pay attention please," pointing to, and/or tapping.

The child is oriented, both nonverbal and verbal towards the task. He shows task-oriented behavior. Examples of child behavior are bending over, pointing out, and/or looking at what the diagnostician is pointing out.

(2) When the Diagnostician Asks Questions That Elicit Understanding, the Child Answers. The diagnostician asks questions to determine what the child may or may not know in order to activate (prior) knowledge. Some basic knowledge is necessary in order to complete the task, the diagnostician checks whether the child is able to carry out the task. Examples of verbal behaviors are "What is this form?," "What color is this?," "Is it large or small?"

The child gives an explanation and expresses his thoughts. The child gives incorrect and/or correct answers to the questions of the diagnostician. Examples of behaviors are: thinking aloud, labeling, and/or (in) correctly explaining the thinking process.

(3) When the Diagnostician Provides Feedback the Child Responds to It. The diagnostician offers encouraging remarks and praise to elicit feelings of competence and mastery within the child. He compliments and gives feedback. Examples of behaviors are "Yes, you're right, because...," "I know you can do it!", nodding, winking, giving the child a pat on the back, and/or smiling.

The child is receiving the feedback of the diagnostician and is responding to it. He shows behavior that refers to mastery. Willingness to explore and to take the challenge is visible in his behavior. Examples of behaviors are "I know how to do it already!," "Thanks!," nodding, smiling, and/or blushing.

(4) When the Diagnostician Teaches Strategies the Child Uses Them. The diagnostician explains and teaches the child thinking strategies. He helps the child to define the problem and to find out effective ways to solve the task. Examples of this kind of behavior are "can you continue?," "Let me give you some advice about your mode of operation," "Got them all?," demonstrating, modeling and/or participating.

The child acts and implements the strategies that are offered. His actions can be correct or incorrect. Examples of behaviors are asking for assistance, checking out loud, accepting assistance, imitating, and/or acting.
1.5. Research Questions. The study presented was carried out to reveal how scaffolding defined from a dynamic system approach emerges during the training phase of a learning potential test. The investigation aimed at showing whether scaffolding differs between children with learning gains in comparison to children without learning gains. Three research questions were answered.

(1) Which sequences of scaffolding emerge during the training phase in both research conditions?

(2) Does frequency of sequences of scaffolding change during the training phase between the conditions?

(3) Do the type and number of sequences of scaffolding differ between conditions?

\section{Method}

2.1. Subjects. The sample included four boys and four girls from Kindergartens from regular primary schools and the diagnostician who carried out the training. For the purpose of the study, eight children were selected from a dataset [26] which consisted of 34 children from Grade 2 of regular primary schools. Their mean age was 73.4 months $(\mathrm{SD}=4.33)$. The selection was based upon the following criteria: all children had completed one year of kindergarten; the numbers of boys and girls were alike as well as the composition of the two conditions: two boys and two girls with learning gains and two boys and two girls with no learning gains. From all children, information about duration of the training phase and results on the pretest and the posttest were available. The data are listed in Table 1.

2.2. Materials: Subtest Classification of the ACFS. The subtest classification of the applied cognitive functions scales [7] was used to collect the data for the study of Hiddink [26]. For the pretest, each child is individually invited to group threedimensional wooden cubes that are based on the characteristics color, shape, and size. The cubes are 36 blocks of mixed characteristics. The blocks are shown in Figure 2. Following introductory comments, the child is invited to "Show me how you can make groups with these blocks." If the child is successful, he is told: "Show me another way that you can make groups with these blocks." The posttest is the same as the pretest. The maximum score of pretest and post test is seven points. The child receives a minimum of four points for correct use of blocks followed by one point for each correct grouping. The subtest was videotaped with a camera on a stand.

After the pretest, a so-called conversational intervention takes place in the training phase. Two-dimensional cards varying in color, shape, and size are placed in front of the child, and he is pointed at meaningful information that allows successful classification of the cards in three subtasks that are presented one after the other. Figure 3 shows the three classifications that are carried out with the cards.

There is no fixed order of the three subtasks. The diagnostician provides help to the child to sort the cards and 
TABLE 1: Age in months, pretest, and posttest scores, duration of the training phase in seconds for the whole task and each subtask separately for each child of the sample. The "learning gains" condition includes the bold faced students.

\begin{tabular}{|c|c|c|c|c|c|c|c|}
\hline Sex & $\begin{array}{l}\text { Age in } \\
\text { months }\end{array}$ & Score pretest & Score posttest & Duration of the training phase & Duration of task 1 & Duration of task 2 & Duration of task 3 \\
\hline Girl & 74 & 2 & 4 & 449 & 82 & 146 & 107 \\
\hline Boy & 71 & 1 & 3 & 666 & 139 & 168 & 216 \\
\hline Girl & 76 & 2 & 7 & 338 & 53 & 89 & 94 \\
\hline Boy & 75 & 2 & 5 & 372 & 122 & 98 & 114 \\
\hline Girl & 77 & 1 & 1 & 422 & 45 & 145 & 116 \\
\hline Boy & 77 & 4 & 3 & 435 & 36 & 149 & 118 \\
\hline Girl & 63 & 1 & 1 & 532 & 72 & 188 & 172 \\
\hline Boy & 74 & 5 & 5 & 434 & 121 & 115 & 118 \\
\hline
\end{tabular}

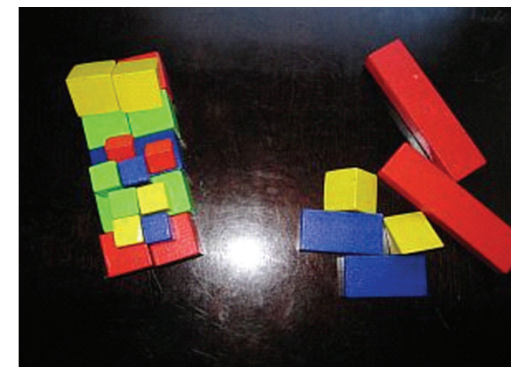

(a)

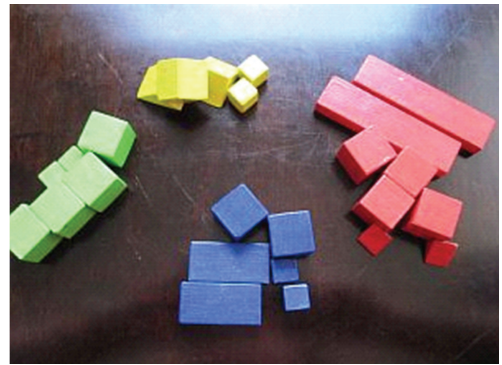

(b)

FIgURE 2: Examples of results of pretest (a) and posttest (b) of one child.

make the groups. After completion of the training phase, the posttest is offered.

2.3. Procedure. The microgenetic data analysis was carried out with the videotapes of the training phase. First, the video recordings were used to transcribe the behaviors. Next, the behaviors were categorized with a coding system. The coding system was based upon an existing coding system [27]. It included categories of behaviors during the task as verbal, nonverbal, and perceptual behaviors. Variables were added to the list after observing the video registrations with the characteristics of diagnostician behavior and child behavior [28, 29]. Mediacoder [30] was applied to analyze the videotapes with the coding list. Mediacoder is a computer program that allows viewing video material and scoring observed behaviors at the same time. The program exports the coding directly into an Excel file of columns that specify lists of behavioral codes and the time that the behavior occurs. The results of the categorization of behaviors are read into Excel files. The file enables computations of frequencies of behaviors and relationships between the frequencies in order to answer the three research questions.

2.4. Interrater Reliability. The interobserver reliability for the categories in the coding system was computed with Cohen's Kappa and a Monte Carlo Analysis. For Cohen's Kappa, an interobserver reliability greater than 0.70 is considered satisfactory, and for the Monte Carlo Analysis, it should be greater than 0.60 . Furthermore, the change reliability has to be lower than the interobserver reliability. Table 2 reveals that all agreement scores were reliable, that is, are very unlikely based on similarity due to chance.

2.5. Data Analysis. In order to answer the research questions, the number of verbal, nonverbal, and perceptive behaviors of the diagnostician and each child were computed as well as the number of each sequence of scaffolding. The behaviors during the introduction and the ending of the task were not included in the analysis. Moreover, the following timeepisodes were applied: The diagnostician responds within three seconds after child behavior. the child responds within eight seconds after diagnostician behavior. The number of sequences was computed per subtask and as an overall number.

\section{Results}

The results are presented by showing the findings of the two conditions per research question.

3.1. Which Sequences of Scaffolding Emerge during the Training Phase? The results are presented in Figure 4 as relative frequencies of the four sequences of scaffolding: when the diagnostician asks for attention, the child shows task-oriented behavior; when the diagnostician asks for understanding, the child answers (in) correct; when the diagnostician provides feedback, the child receives it and responds to it, and 


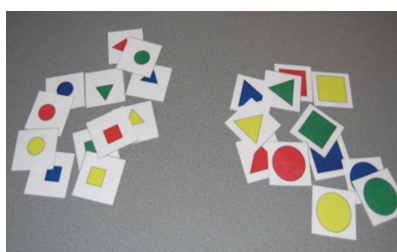

(a)

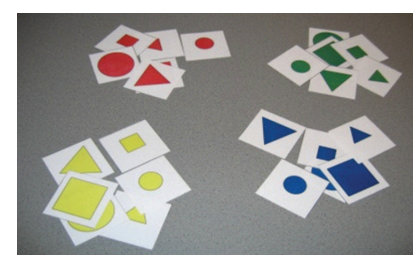

(b)

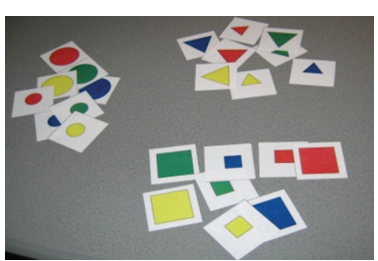

(c)

FIGURE 3: Examples of the results of the training phase for each characteristic.

TABle 2: Interobserver reliability: Cohen's Kappa and Monte Carlo Analysis.

\begin{tabular}{lccc}
\hline Main category & Cohen's Kappa & $\begin{array}{c}\text { Monte Carlo Analysis } \\
\text { Inter observer reliability }\end{array}$ & $\begin{array}{c}\text { Monte Carlo Analysis } \\
\text { chance reliability }\end{array}$ \\
\hline Diagnostician verbal & 0.85 & 0.67 & 0.24 \\
Diagnostician nonverbal & 0.89 & 0.78 & 0.44 \\
Diagnostician perceptual & 0.86 & 0.60 & 0.32 \\
Child verbal & 0.76 & 0.94 & 0.87 \\
Child nonverbal & 0.81 & 0.71 & 0.35 \\
Child perceptual & 0.75 & 0.60 & 0.32 \\
\hline
\end{tabular}

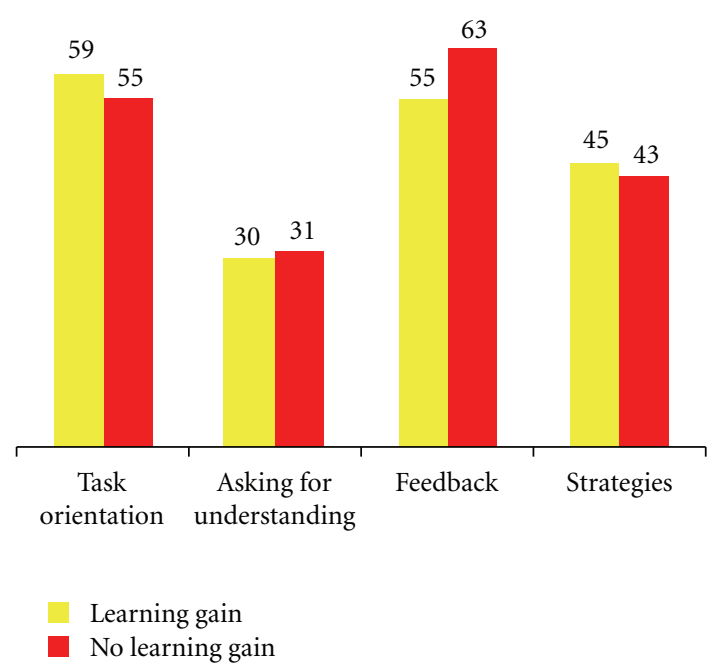

FIGURE 4: Frequencies and percentages of the four sequences per condition.

when the diagnostician is teaching strategies, the child acts upon it.

Figure 4 shows that each sequence type was found in both conditions. There were no significant differences in the number of sequences of scaffolding between the conditions.

\subsection{Does Frequency of Sequences of Scaffolding Change during} the Training Phase? The proportion of each sequence of scaffolding changed from subtask 1 to 3 for both conditions. With regard to the frequency of task orientation, a similar pattern emerged over time in both groups: the sequence occurs relatively more often during subtasks 2 and 3 than during subtask 1 . The other three sequences of scaffolding show different patterns for both conditions. The proportion of asking for understanding in the transition from subtask 1 to subtask 3 decreased in the condition "Learning gains" compared to the condition "No learning gains." With regard to the sequence of feedback, a difference between both conditions is revealed: The frequency decreases over time in the condition "Learning gains" and increases over time in the condition "No learning gains." The sequence of strategies reveals an opposite direction when both conditions are compared. The frequency of sequences of scaffolding per condition is presented in Figure 5.

3.3. Do the Type and Number of Sequences of Scaffolding Differ Between the Conditions? The results from the comparison between the conditions suggest that differences exist between the conditions. The findings allow visual inspection of the frequency of the sequences and changes over time from subtask 1 to 2 and 3 . The results, however, allow different interpretations on the underlying dynamics of the sequences to explain why the diagnostician and children behaved as they did. One explanation is that the sequence of task orientation occurs more often for both groups during subtask 2 than during subtask 1 since the diagnostician has observed the child and realizes that the child needs to be focused. A second explanation is that the child needs some time to get used to the way the diagnostician calls for attention and it is until task 2 before he understands what is expected of him.

3.4. Hierarchy of Sequences for Each Task with Regard to the Four Sequences Per Condition. Since the proceedings from sequences from one task to the next adds to understanding how learning gains are reached, the number of sequences of scaffolding may also add to grasp the dynamics of effective scaffolding. It could be expected that sequences in subtask 1 will be repeated in subtasks 2 and 3 on a higher level of scaffolding, such as eliciting more strategic behavior of 

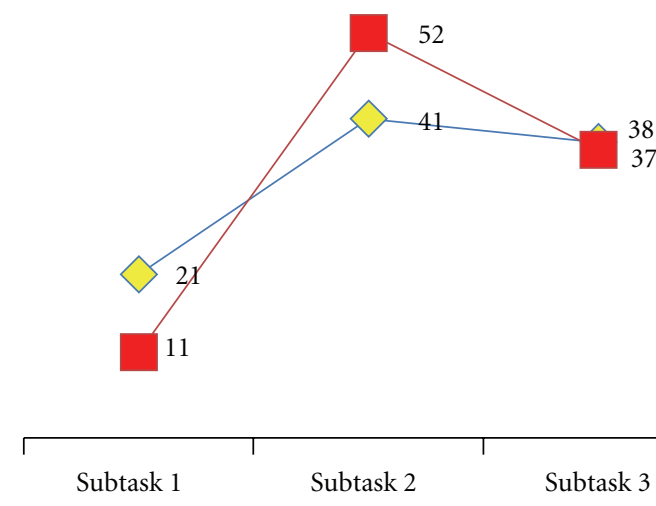

Subtask 1

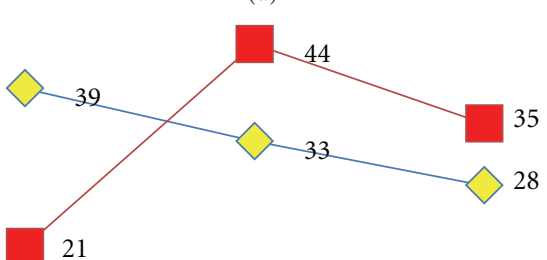

21
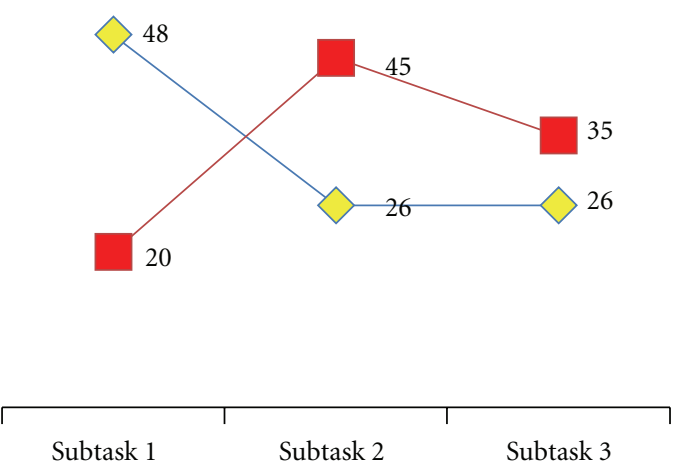

(b)

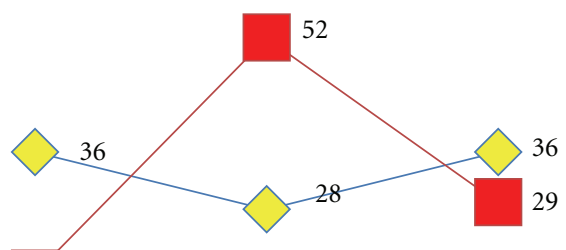

19

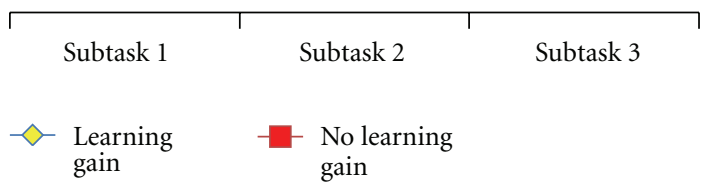

(c)

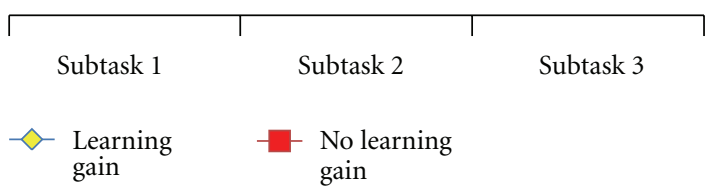

(d)

FIGURE 5: Proportions of sequences of scaffolding per subtask of task orientation, asking for understanding, feedback, and strategies.

TABLE 3: Ranking of sequences for subtask 1, 2, and 3 for research condition "Learning gains" and "No learning gains."

\begin{tabular}{llll}
\hline Condition & Subtask 1 & Subtask 2 & Subtask 3 \\
\hline \multirow{3}{*}{ Learning gains } & $\begin{array}{l}\text { Asking for understanding, } \\
\text { feedback,strategies, task } \\
\text { orientation }\end{array}$ & $\begin{array}{l}\text { Task orientation, feedback, } \\
\text { strategies, asking for } \\
\text { understanding }\end{array}$ & $\begin{array}{l}\text { Task orientation, strategies, } \\
\text { feedback, asking for } \\
\text { understanding }\end{array}$ \\
\hline \multirow{3}{*}{ No learning gains } & $\begin{array}{l}\text { Feedback, asking for } \\
\text { understanding, strategies, } \\
\text { task orientation }\end{array}$ & $\begin{array}{l}\text { Task orientation/strategies, } \\
\text { asking for understanding, } \\
\text { feedback }\end{array}$ & $\begin{array}{l}\text { Task orientation, } \\
\text { feedback/asking for } \\
\text { understanding, strategies }\end{array}$ \\
\hline
\end{tabular}

the child in order to elicit the child's understanding of the task as a sorting task. Table 3 shows the ranking of the four sequences per condition within each subtask.

Table 3 shows that in both conditions the frequency of task orientation is least occurring in subtask 1 and most often in subtasks 2 and 3. Only in the condition "Learning gains," the frequency of strategies increases from subtask 2 to 3 , and in the condition "No learning gains" the frequency of Strategies is the least one used in subtask 3. Again, multiple explanations of the findings are possible. The first one is that the diagnostician lets go of the aim to elicit the child's strategic insight when the proceedings in subtask 2 reveal that the child dose not seem to grasp the rule of classification and move back to a lower level of scaffolding. An alternative explanation is that the diagnostician has not grasped the child's level of understanding of the subtask and misinterprets the child's behavior as being low in potential to understand the subtask.

\subsection{Frequency of Sequences, Rainbow Plots, and Transcript Excerpts That Allow In-Depth View of the Scaffolding Process with Two Boys from the Sample}

3.5.1. Frequency of Sequences. The results of the comparisons of conditions allow the conclusion that dynamics of the training phase differ between the condition "Learning gains" and "No learning gains." To make sense of the underlying dynamics of the sequences of scaffolding the frequencies of the four types of sequences are presented in Figure 6 for one of the boys with learning gains and one of the boys without learning gains. 


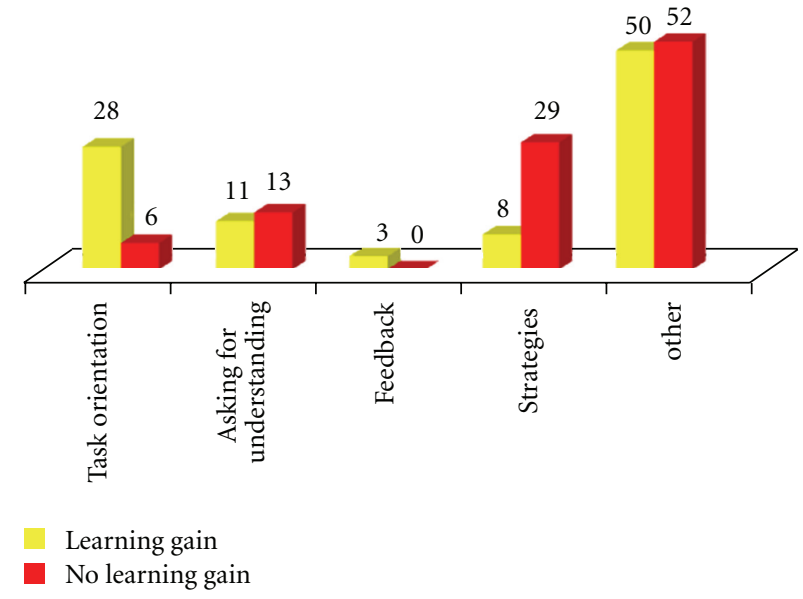

Figure 6: The sequences, Task Orientation, Asking for Understanding, Feedback, and Strategies for one boy with learning gains and one boy without learning gains from the sample.

Figure 6 shows that the sequences of Task orientation are more frequent with the boy with learning gains compared to the boy without learning gains. The sequences of Asking for understanding and Strategies are more frequent with the boy without learning gains compared to the boy with learning gains. This finding suggests that the sequences of scaffolding with the boy with learning gains are more effective: $\mathrm{He}$ is focusing on the task, whereas the boy without learning gains is involved in sequences of trying to grasp what the task is about and being elicited to rule oriented behavior.

3.5.2. Rainbow Plot of the Boy with Learning Gains. Rainbow plots allow an in-depth view of the sequences. Figure 7 represents the sequence Task orientation of the boy with learning gains. Figure 8 shows those of the boy without learning gains. In both figures, the sequences from subtask 1 to 2 and from subtask 2 to 3 are visualized. The rainbow plots in Figures 7 and 8 highlight the behaviors associated with one single sequence. The white areas in the rainbow plot do not refer to periods when nothing happened, but to periods when other behaviors (such as behaviors belonging to the other three sequences) occurred. In reality, the sequences occur simultaneously and influence each other continuously. Level 1 (bottom level) refers to behavior of the diagnostician who is asking for attention of the boy. Level 2 (upper level) refers to the child's behavior that refers to paying attention and acting. The time for the three subtasks differs between the boys, from 614 seconds (Figure 7) for the boy with learning gains to 363 seconds (Figure 8 ) for the boy without learning gains.

The barcodes in Figure 7 show that the boy first pays attention and then acts upon it. The blue bars that refer to acting are each time preceded by yellow bars that refer to paying attention. This is consistent with our finding in Figure 6 that his reaction to the diagnostician consists mostly of paying attention instead of acting immediately. Moreover, the barcodes show that the boy is sorting the cards in each subtask most of the time. The time that he spends on sorting without being interrupted is the longest in subtask 3 . This suggests that he sorted well and that the diagnostician reflects upon the result of the sorting only after completing the subtask.

3.5.3. Transcript of the Boy with Learning Gains. The transcript shows how the child is invited to figure out the change from sorting cards by color to sorting cards by form.

Transcript: Second 229 to 278.

Diagnostician: “OK! Let's have a look. That one, ... is it the same as this one? (Points at two cards with different forms).

Boy: "Uhm. . a bit."

Diagnostician: "A bit? What not?"

Boy: "Round"

Diagnostician: "Round. What form is this?"

Boy: "A triangle".

Diagnostician: "That is not a triangle. What is it?"

Boy: "A circle".

Diagnostician: "OK, where will you put the triangles?”

Boy: "Uhm.." (points at a place on the table).

Diagnostician: "Uhm.. here? OK, and the circles?"

Boy: (points at another place on the table).

Diagnostician: "Here? OK. Now we are looking at form. We will make groups on form. Is that a triangle?" (Points at a card and helps with moving the card).

3.5.4. Rainbow Plot of the Boy without Learning Gains. Level 1 (bottom level) refers to behavior of the diagnostician who is asking for attention of the boy. Level 2 (upper level) refers to the child's behavior that refers to paying attention and acting. The time for the three subtasks differs between the boys, from 614 seconds (Figure 7) for the boy with learning gains to 363 seconds (Figure 8 ) for the boy without learning gains.

The barcodes in Figure 8 show that the blue bars that refer to acting are not always preceded by yellow bars that refer to paying attention. This finding is consistent with the finding presented in Figure 6 that his reaction to the diagnostician consists mainly of acting immediately.

Moreover, the barcodes show that the boy is sorting the cards in each task most of the time, but in the beginning of both subtasks 2 and 3, he is interrupted by the diagnostician many times.

3.5.5. Transcript of the Boy without Learning Gains. The excerpt of the beginning of subtask 2 reveals a little of the actual scaffolding of the diagnostician: It does not seem very effective. The transcript shows how the child is invited to figure out the change from sorting cards by color to sorting cards by form. 


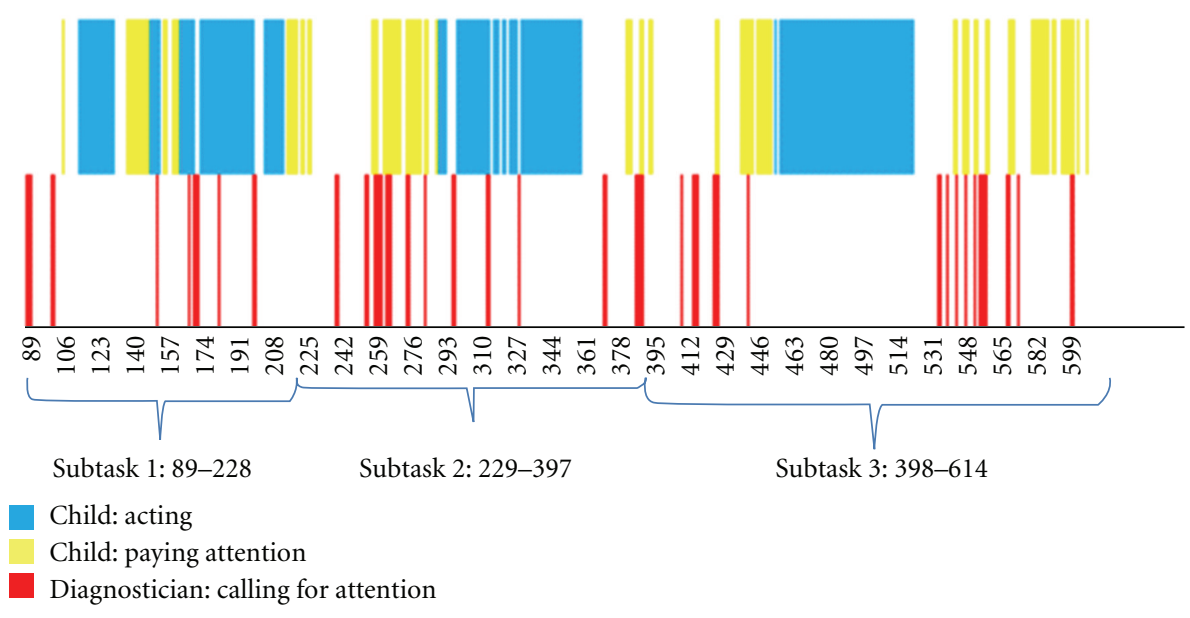

FIGURE 7: Sequences of scaffolding related to task orientation from a boy with learning gain of each subtask over time.

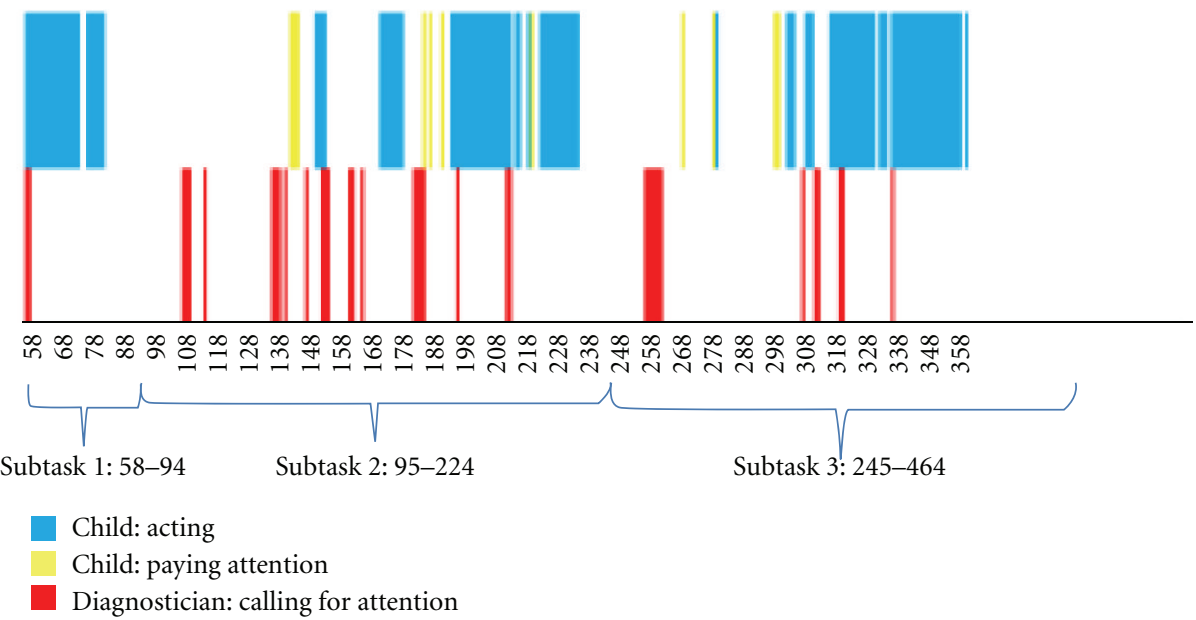

FIGURE 8: Sequences of scaffolding related to task orientation from a boy without learning gain for each subtask over time.

\section{Transcript: Second 59 to 149.}

Diagnostician: "Yes, you can help me, yes", cause you can also ... Do you know how you can sort the cards in another way?

Child: "Uhm.." (pulls his shoulders up, talks unintelligible).

Diagnostician: "Yes? How?"

Child: (moves the cards around).

Diagnostician: "What do you do now?"

Child: (takes two cards and puts them together).

Diagnostician: "Why do you put these together?"

Child: (looks at the diagnostician) "Colors together"

Diagnostician: "Colors together, but... (takes the two cards that the child had picked), but look here, these are two squares (puts the two squares together in front of the child). And this is a square too. So when I put this one there (puts another square to the group of two cards). Should I put that card there as well? (points at a card). Is that a square too?"

Child: "No."

Diagnostician: "No? What is it then?"

Child: "A round one."

Although the rainbow plots and the excerpts reveal just a little of the actual behavior that underlies the sequences, they powerfully illustrate the differences with regard to task orientation of both boys. Many questions can be raised about the achieved balance between a child's need of assistance and the diagnostician adjustments or success of scaffolding the child understanding of the task in that the cards have to be sorted after color in the first subtask and after form in the second subtask. 


\section{Conclusions and Discussion}

4.1. Conclusions. The study aimed at understanding which sequences during the training phase of a learning potential test can be understood as predictors of learning potential. The first research question was whether the sequences of scaffolding would emerge during the training phase. There were no significant differences in the number of sequences between the conditions. The results from the comparison between the conditions suggest that changes occurred in the relative frequency of each type of sequence from subtask 1 to 3: differential dynamics underlie the achievement of learning gains since differences were detected between the conditions. Also, the hierarchy of frequency of sequences of scaffolding changed between the three subtasks and differed between the conditions. The description of the findings of a boy from each condition in frequency per sequence, rainbow plot, and representative transcript allowed us to show emergence of sequences over time. Although the description of two boys does not allow final conclusions, the findings underline the sharp differences with regard to the dynamic system that is at work during the training phase of a learning potential test.

With the findings of the study, a first glance is offered about the way a dynamic system approach can enlighten the mutual interaction processes that emerge and stabilize over the course of less than 10 minutes: The rainbow plots reveal the unique sequences that unfold during the training phase of a learning potential test. Although the importance of sequences in the task from an individual point of view cannot be emphasized enough, we also point at the importance of attitude and experience of the diagnostician. The better the diagnostician is able to scaffold the more the child gets the opportunity to show what he or she (with help) can do [11].

4.2. Discussion. The findings reveal that the training phase of a learning potential test includes several sequences of scaffolding that lead to more or less stability of behaviors of both diagnostician and child within the teaching-learning event. In the case of the sequences of task orientation and feedback, the differences between conditions suggest that these are related to the formation of learning gains.

With regard to the role of feedback in the scaffolding process we draw attention to the following. Hattie and Timperely [31, page 81] define feedback as "information provided by an agent (i.e., teacher, self et cetera) regarding aspects of one's performance or understanding." This definition suggests a one-way direction of feedback. Our findings, however, suggest that feedback is also child driven. The child shows behavior that elicits diagnostician's behavior to reduce the discrepancy between current and desired understanding of the child. So, when Hattie and Timperely conclude from a meta-analysis on feedback studies that feedback is especially effective when its content is timely and meaningful during the process of task performance, we should keep in mind that timely and meaningful refers to both trainer and child behavior as both parties are actively involved. From this perspective, effective scaffolding is strongly dependent upon the way feedback is used: it should allow the learner to grasp the learning process that is supposedly taking place while being supported in the task.

A second finding of the study is that we were able to show that regularities or paths during the training phase occur, which in turn allowed us to identify irregular aspects in the sequences or variability. Although the number of subjects in the study is limited, we showed convincingly that paths emerge during the training phase. We can add that variability was revealed on group and individual level, such as described by the rainbow plots and the transcript fragments. Flynn and Siegler [32] pointed at this advantage in earlier studies.

The dynamic systems theory was used as a theoretical framework in order to improve understanding on how children learn to classify cards that supposedly increase their grasp on the rules for classification with three dimensional blocks. Based on the occurrence of the four sequences of scaffolding: attention to the task, understanding, feedback, and strategies, the findings show that all of the sequences seemed to matter to complete the subtasks. Yet, some children profited from the training and showed learning gains in the posttest whereas other children from the sample did not. The findings suggest that other factors than the behaviors of the participants play a role in interactions. One factor could be the role of external factors while teaching and responding to teaching efforts. Kennedy [33] suggests that we may be overestimating the influence of personal characteristics of the behaviors, in this case of the diagnostician and the child, and underestimate the influence of the assessment context. The situation that the diagnostician faces during the training phase may provide important and underappreciated influences on his assessment practice, such as the effect on his behavior of testing one child after the other who each respond differently to the situation. From the perspective of the child, the situation is peculiar as he or she has never met the diagnostician before. From the pretest to the training phase, the child encounters a change in the task, from three dimensional to two dimensional, from expected to sort the blocks without instruction to waiting for explanation, and then being supposed to complete the task with the diagnostician's assistance. Alternative explanations such as these are familiar from a dynamic systems approach [14]. Each of the alternatives would require a new model to be tested, including theory-based variables to investigate in subsequent studies. Such steps would allow further consolidation of the principles that lie beneath effective scaffolding during the training phase of a learning potential test.

It should be kept in mind that the findings do not allow interpretations with regard to causality of sequences. Moreover, only the frequencies on the level of four sequences were obtained. Uncovering a chain of sequences that are interrelated would allow a better grasp on the reciprocity of child and diagnostician behavior. It may also be expected that there are more than four sequences at work during the training phase, such as emotional triggers or reactions to the novelty of the task. A next step for the purpose to detect learning potential through a dynamics systems approach would, therefore, be to further develop a theoretical prescriptive model of variables such as suggested in Figure 1. The 
investigation following this model would then allow causal inferences of the sequences that are detected.

\section{References}

[1] C. S. Lidz, Ed., Dynamic Assessment. An Interactional Approach to Evaluating Learning Potential, The Guilford Press, New York, NY, USA, 1987.

[2] L. S. Vygotsky, Mind in Society: The Development of Higher Psychological Processes, Harvard University Press, Cambridge, Mass, USA, 1978, Edited by M. Cole, V. John-Steiner, S. Scribner, and E. Soubermann.

[3] J. D. Day, J. L. Engelhardt, S. E. Maxwell, and E. E. Erika, "Comparison of static and dynamic assessment procedures and their relation to independent performance," Journal of Educational Psychology, vol. 89, no. 2, pp. 358-368, 1997.

[4] C. S. Lidz and G. M. van der Aalsvoort, "Usefulness of the application of cognitive functions scales with young children from the Netherlands," Transylvanian Journal of Psychology, vol. 6, no. 1, pp. 25-44, 2005.

[5] W. C. M. Resing, "Understanding potential, about dynamic testing, variability in problem solving solutions and learning potential with children," Leiden University, Leiden, The Netherlands, professorial speech, 2006.

[6] G. M. Van Der Aalsvoort and C. S. Lidz, "A cross-cultural validation study of the application of cognitive functions scale: a dynamic assessment procedure, with Dutch first grade students from regular primary schools," Journal of Applied School Psychology, vol. 24, no. 1, pp. 91-108, 2007.

[7] C. S. Lidz and R. H. Jepsen, "The Application of Cognitive Function Scale (ACFS): an example of curriculumbased dynamic assessment," in Dynamic Assessment: Prevailing Models en Applications, C. S. Lidz and J. G. Elliott, Eds., pp. 407-439, JAI/Elsevier Science, Amsterdam, The Netherlands, 2000.

[8] R. Feuerstein, Dynamic Assessment of Retarded Performers, University Park Press, Baltimore, Md, USA, 1979.

[9] P. S. Klein and A. J. Tannenbaum, To Be Young and Gifted, Ablex Publishing Corporation, Norwood, NJ, USA, 1992.

[10] C. S. Lidz, Reaction to Mediation Scales, Personal correspondence with the author, 1997.

[11] C. S. Lidz and H. C. Haywood, Dynamic Assessment in Practice: Clinical and Educational Applications, Cambridge University Press, Cambridge, UK, 2007.

[12] D. Tzuriel, Dynamic Assessment of Young Children, Kluwer Academic/Plenum Publishers, New York, NY, USA, 2001.

[13] P. van Geert, "Dynamische systeemtheorie van ontwikkeling, Mogelijke consequenties voor de benadering van de ontwikkeling van 'afwijkende' kinderen, diagnostiek, behandeling en evaluatie van interventies," in De Ontwikkeling van Kinderen met Problemen: Gewoon Anders, E. J. Knorth, H. Nakken, C. E. Oenema-Mostert, A. J. J. M. Ruijssenaars, and J. Strijker, Eds., pp. 28-43, Garant, Antwerp, Belgium, 2008.

[14] P. van Geert, "Play, an approach from the perspective of dynamic system theory," University of Applied Sciences, Utrecht, The Netherlands, 2009.

[15] A. Ensing, G. M. van der Aalsvoort, and P. van Geert, "Dynamic patterns of teacher-child interaction and the way they provide insight in the learning potential of a five-year old child," in Learning, Social Interaction and Diversity-Exploring Identities in School Practices, E. Hjörne, G. van der Aalsvoort, and G. de Abreu, Eds., pp. 163-175, Sense, Rotterdam, The Netherlands, 2012.
[16] P. van Geert and H. Steenbeek, "Explaining after by before: basic aspects of a dynamic systems approach to the study of development," Developmental Review, vol. 25, no. 3-4, pp. 408-442, 2005.

[17] H. W. Steenbeek and P. L. C. van Geert, "A theory and dynamic model of dyadic interaction: concerns, appraisals, and contagiousness in a developmental context," Developmental Review, vol. 27, no. 1, pp. 1-40, 2007.

[18] G. M. van der Aalsvoort, P. van Geert, and H. W. Steenbeek, "Microgenetic Methodology: possibilities with regard to research on learning and instruction," in Investigating Classroom Interaction: Methodologies in Action, K. Kumpulainen, C. Hmelo-Silver, and M. César, Eds., pp. 203-227, Sense Publishers, Rotterdam, The Netherlands, 2009.

[19] D. K. Meyer and J. C. Turner, "Using instructional discourse analysis to study the scaffolding of student self-regulation," Educational Psychologist, vol. 37, no. 1, pp. 17-25, 2002.

[20] D. Wood, J. S. Bruner, and G. Ross, "The role of tutoring in problem solving," Journal of Child Psychology and Psychiatry, vol. 17, pp. 89-100, 1976.

[21] I. Molenaar, C. A. M. Van Boxtel, and P. J. C. Sleegers, "The effects of scaffolding metacognitive activities in small groups," Computers in Human Behavior, vol. 26, no. 6, pp. 1727-1738, 2010.

[22] J. V. D. Pol, M. Volman, and J. Beishuizen, "Patterns of contingent teaching in teacher-student interaction," Learning and Instruction, vol. 21, no. 1, pp. 46-57, 2011.

[23] R. S. Siegler and K. Crowley, "The microgenetic method: a direct means for studying cognitive development," American Psychologist, vol. 46, no. 6, pp. 606-620, 1991.

[24] R. S. Siegler and Z. Chen, "Developmental differences in rule learning: a microgenetic analysis," Cognitive Psychology, vol. 36, no. 3, pp. 273-310, 1998.

[25] C. S. Lidz, Practitioner's Guide to Dynamic Assessment, The Guilford Press, New York, NY ,USA, 1991.

[26] F. Hiddink, The relationship between parent-child interactions and learning gains with the subtest of Classification: validation of the ACFS, M.S. thesis, University of Groningen, Developmental Psychology, Groningen, The Netherlands, 2009.

[27] A. Ensing and E. B. Hensema, Categories, University of Groningen, Department of Developmental Psychology, Groningen, The Netherlands, 2008.

[28] F. van Loo and G. M. van der Aalsvoort, "Are effective dynamic interaction patterns related to learning gains?" in Proceedings of the Biennial Meeting of EARLI SIG Social interaction in learning and instruction \& SIG Learning and Teaching in Culturally Diverse Settings, University of Utrecht, Utrecht, The Netherlands, 2010.

[29] F. van Loo and G. M. van der Aalsvoort, "Interaction patterns leading to learning gains: how to measure and how to interpret?" in Proceedings of the Biennial Meeting of EARLI SIG Special Educational Needs, Frankfurt, Germany, 2010.

[30] J. Bos and H. W. Steenbeek, MediaCoder 2008, A Simple Application for Coding Behavior within Media Files. Dutch Manual, University of Groningen, Faculty of Behavioral Sciences, Groningen, The Netherlands, 2008.

[31] J. Hattie and H. Timperley, "The power of feedback," Review of Educational Research, vol. 77, no. 1, pp. 81-112, 2007.

[32] E. Flynn and R. Siegler, "Measuring change: current trends and future directions in microgenetic research," Infant and Child Development, vol. 16, no. 1, pp. 135-149, 2007.

[33] M. M. Kennedy, "Attribution error and the quest for teacher quality," Educational Researcher, vol. 39, no. 8, pp. 591-598, 2011. 

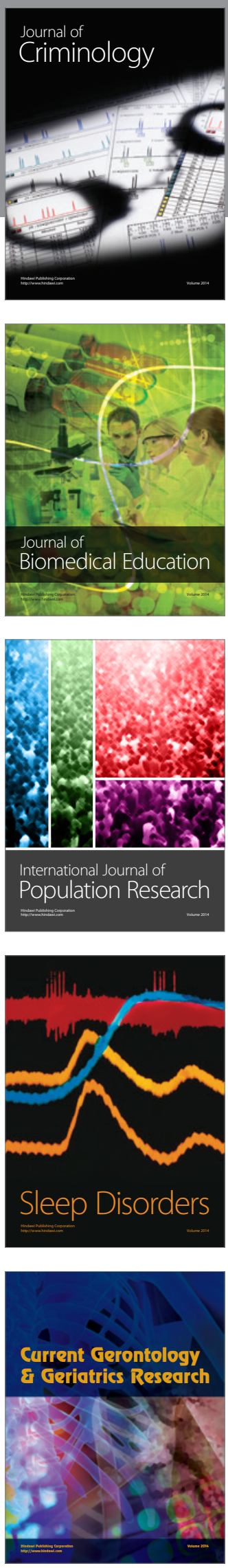
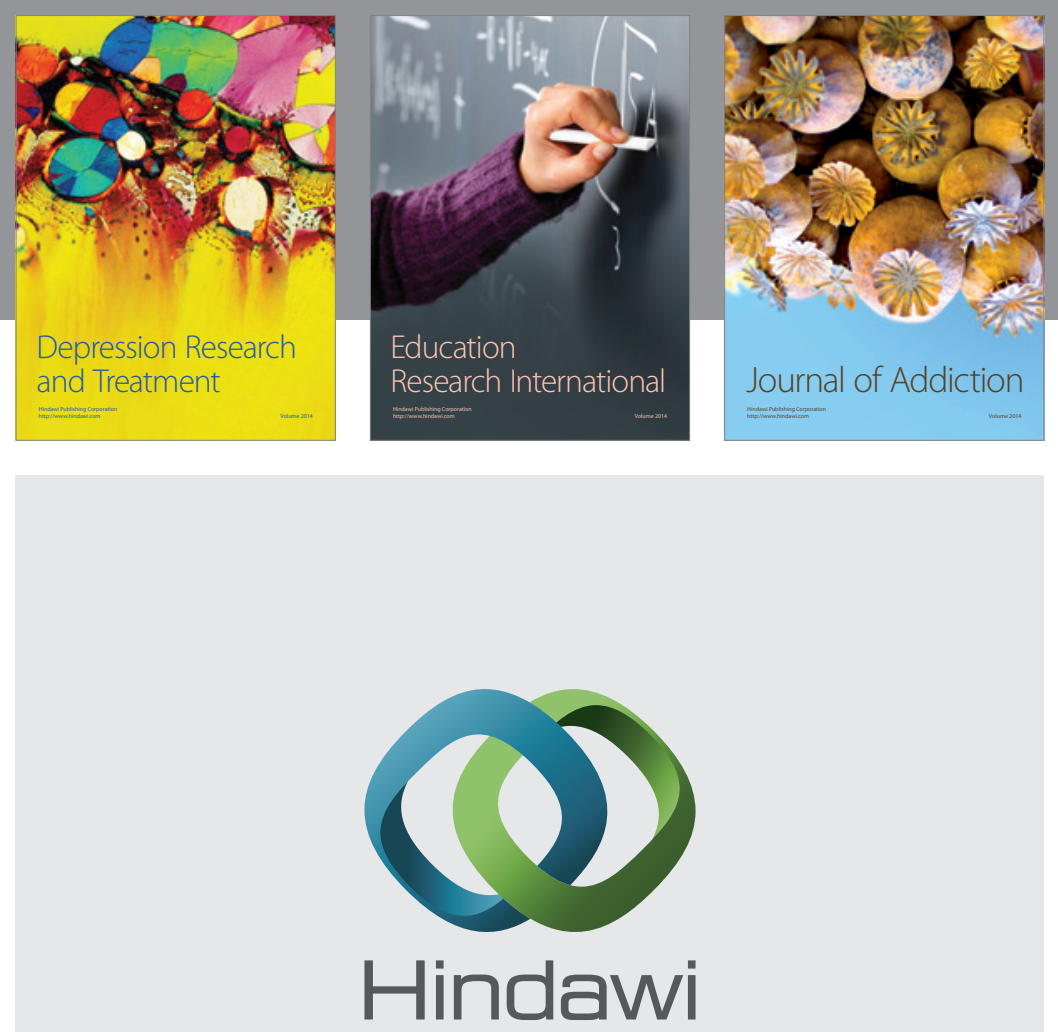

Submit your manuscripts at

http://www.hindawi.com

Child Development Research
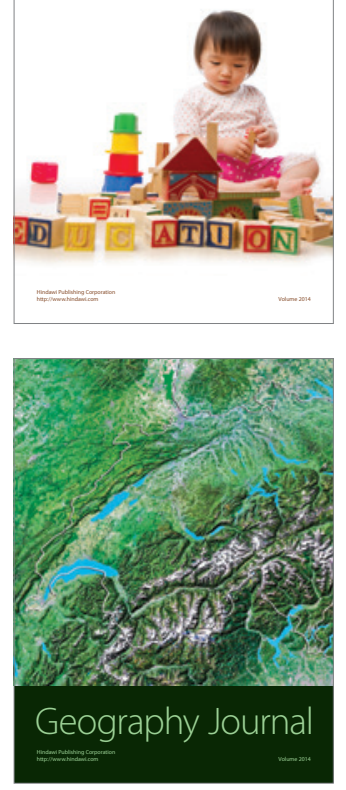

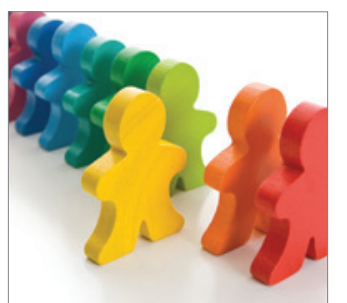

Autism

Research and Treatment
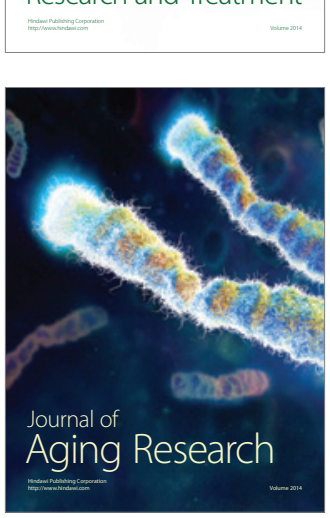
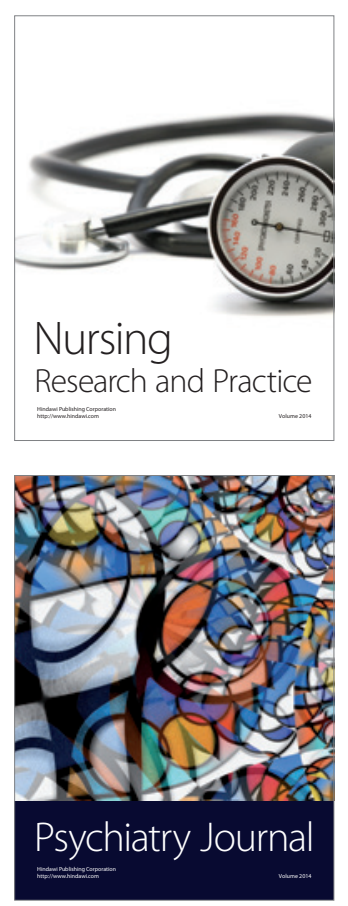
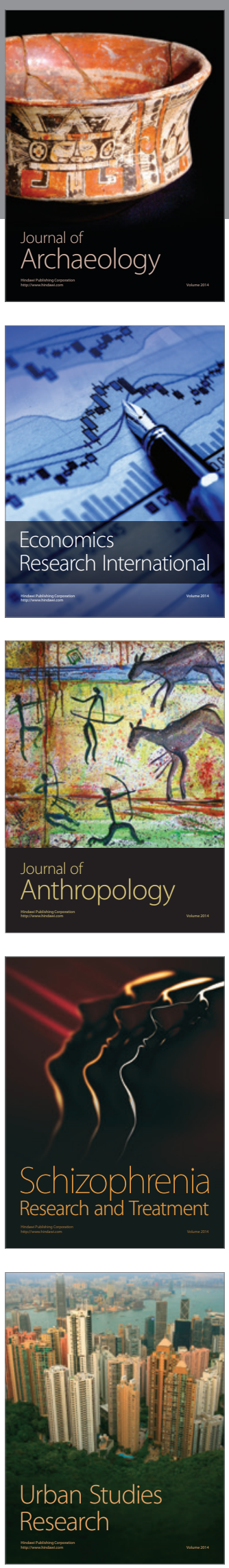